\title{
ПРАВОВАЯ ОХРАНА ИЗОБРАЖЕНИЯ ГРАЖДАНИНА: ОСОБЕННОСТИ И ПРОБЛЕМЫ ПРАВОВОГО РЕГУЛИРОВАНИЯ
}

\section{LEGAL PROTECTION OF A CITIZEN'S IMAGE: FEATURES AND PROBLEMS OF LEGAL REGULATION}

\section{N. Safin \\ D. Proskurina}

Summary: In their research, the authors analyze the current approaches to the concept of the image of a citizen and its doctrinal and dogmatic aspects. The problems of legal protection of the image of a citizen, which are considered mainly in a civilistic way, are brought up for consideration. By analyzing the modern practice of law enforcement, the authors highlight the problems of legal regulation that arise regarding the image and appearance of a citizen. In particular, issues of civil protection and protection of the citizen's own image. Possible ways of solving these problems are considered. Examples of litigation based on the generalization of law enforcement practice are given.

Keywords: image of a citizen, personal data, the Internet, appearance, misuse of the image, photographs.

\author{
Сафин Никита Игоревич \\ Дальневосточный федеральный университет, \\ г. Владивосток \\ safin99nikita@gmail.com \\ Проскурина Дарья Сергеевна \\ Дальневосточный Федеральный университет, \\ г. Владивосток \\ dariaproscurina@gmail.com
}

Аннотация: В своем исследовании авторы анализируют актуальные подходы к понятию изображения гражданина и его доктринальные, а также догматические аспекты. Выносятся на рассмотрение проблемы правовой охраны изображения гражданина, которые рассматриваются преимущественно в цивилистическом ключе. Путем анализа современной практики правоприменения авторы выделяют проблемы правового регулирования, которые возникают относительно изображения и внешнего облика гражданина. В частности, вопросы гражданско-правовой охраны и защиты собственного изображения гражданина. Рассмотрены возможные пути решения этих проблем. Приведены примеры судебных споров на основе обобщения правоприменительной практики.

Ключевые слова: изображение гражданина, персональные данные, интернет, внешний облик, неправомерное использование изображения, фотографии.

Во-вторых, повсеместное распространение изображений граждан в средствах массовой информации без получения их согласия в том числе для преступных или корыстных целей.

В-третьих, сложности при охране и защите права гражданина на личное изображение

Конституция РФ давно регламентировала тот факт, что человек, его права и свободы высшей ценностью и обязала государство признавать, соблюдать и защищать их (ст. 2). Она охраняет права на личную неприкосновенность (ч. 1 ст. 22), неприкосновенность частной жизни, личную и семейную тайну, защиту своей чести и доброго имени (ч. 1 ст. 23), достоинство личности (ч. 1 ст. 21). Применительно к защите изображения гражданина, данные положения получили свое развитие в статье 152.1 Гражданского кодекса РФ.

Данная норма предусматривает, что любого рода обнародование и использование изображения гражданина (в том числе любые его фотографии, а также видеозаписи или произведения изобразительного искусства, на которых он изображен) допускаются только с согласия этого гражданина. Уже после смерти гражданина его изображение может быть использовано, но исключительно с согласия детей и пережившего супруга, а при их 
отсутствии - с согласия родителей.

Относительно вышеупомянутого положения, Пленум Верховного Суда РФ в своем Постановлении от 23 июня 2015 г. № 25 «О применении судами некоторых положений раздела I части первой Гражданского кодекса Российской Федерации» дал некоторые разъяснения. Так, судебный орган пояснил, что «под обнародованием изображения гражданина по аналогии с положениями ст. 1268 ГК РФ необходимо понимать осуществление действия, которое впервые делает данное изображение доступным для всеобщего сведения путем его опубликования, публичного показа либо любым другим способом, включая размещение его в сети «Интернет» [1].

Однако, необходимо заметить, что нормативная охрана изображения гражданина осуществляется не только на основании ГК РФ. Положения пп. 7 ст. 3 Федерального закона «Об информации, информационных технологиях и о защите информации» от 27.07.2006, предусматривают принцип неприкосновенности частной жизни, недопустимость сбора, хранения, использования и распространения информации о частной жизни лица без его согласия [2]. Надо сказать, что данный принцип является фундаментальной основой всего информационного законодательства, сформировавшегося на данный момент в Российской Федерации и вполне естественно его причастность к сфере правового регулирования изображения гражданина.

Более того, в ст. 3 Федерального закона от 27 июля 2006 г. «О персональных данных» персональные данные определены как любая информация, относящаяся к определенному или определяемому на основании такой информации физическому лицу (субъекту персональных данных) [3].

Таким образом, очевидно - законодатель прямо не указывает на такой объект персональных данных, как «изображение гражданина или человека», однако на основании изображения возможно идентификация конкретной личности, а значит является разумным говорить об изображении гражданина как о форме регламентации персональных данных.

Анализ норм и разъяснений относительно правовой охраны изображения гражданина, позволяет увидеть некоторые пробелы законодательства. Основным подобным пробелом является отсутствие нормативной дефиниции «изображения гражданина», что вынуждает обратиться к доктринальным положениям для анализа способов защиты прав гражданина при использовании его изображения и понимания специфики данной правовой охраны.

Необходимо отметить, что гражданское законода- тельство признает изображение гражданина нематериальным благом, предоставляя ему соответствующую защиту, что вполне логично и обоснованно. Такой вывод можно сделать на основании расположения статьи 152.1 ГК РФ в гл. 8 ГК РФ «Нематериальные блага и их защита» $[4$, C. 37].

В научной литературе присутствует мнение, что изображение гражданина направлено на эмоциональное восприятие другими людьми с помощью известных науке и технике и доступных способов фиксации определенного образа, внешнего облика [5, с. 104]. Из данного вывода следует, что основой изображения гражданина является внешний облик человека. С.П. Гришаев полагает, что «фиксация изображения физического лица не нарушает его право на определенный индивидуальный облик. Она лишь закрепляет этот облик в тот или иной момент» [6].

В соответствии с п. 2 ст. 152.1 ГК РФ лицо, чье право на изображение нарушено, вправе требовать в судебном порядке изъятия из оборота и уничтожения изготовленных в целях введения в гражданский оборот и находящихся в обороте экземпляров материальных носителей с его изображением[7]. Для законного использования изображения гражданина необходимо получение от него согласия. Пленум Верховного Суда РФ в своем Постановлении от 23 июня 2015 г. № 25 «О применении судами некоторых положений раздела I части первой Гражданского кодекса Российской Федерации» пояснил, что данное согласие является сделкой в соответствии со статьей 153 ГК РФ и может быть выражено как в устной или письменной форме, а также путем совершения конклюдентных действий. Причем, если согласие дано устно или с помощью конклюдентных, то таким согласием охватывается использование изображения в том объеме и в тех целях, которые явствуют из обстановки, в которой оно совершалось [1].

Наиболее часто правоприменительная практика сталкивается с незаконным использованием изображений граждан в публикациях СМИ. Заметим, что, как правило, в таких случаях отсутствует согласие граждан, либо его форма является ненадлежащей.

Это могут самые разнообразные случаи, например, публикации, не основанные на действительных событиях, в отрыве от реальных, публикация которых произведена с помощью монтажа или какого-либо искажения изображения, которые ведут к разного рода фальсификациям. Также встречаются публикации изображений, сопровожденных какими-либо оскорбительными надписями или заголовками или же данные публикации сочетаются вместе со сведениями о частной жизни гражданина, его семейной, личной тайне, полученные без его согласия, - в виде журналистских расследований - что 
также является нарушением и подпункта 5 статьи 49 Закона «О средствах массовой информации» со стороны СМИ. Норма обязывает журналиста получать согласие на распространение в СМИ сведений о личной жизни гражданина от самого гражданина или его законного представителя, за исключением случаев, когда это необходимо для защиты общественных интересов [8, с. 118; 9].

На основании полного всестороннего анализа практики правоприменения, мы выявили некоторые основные доводы ответчиков о причинах отказа в получении согласия граждан на публикацию и использования их изображений.

Во-первых, заявления о публичности истца и его известности в обществе, а следовательно (как полагают ответчики) - о возможности распространения информации о его частной жизни в свободной форме. На этом основании, как правило, выдвигается тезис о максимально «узких» границах частной жизни артиста или иной публичной личности, что обосновывает возможность не получать согласия у публичных лиц для использования их изображений.

Так, обратимся к делу по иску артиста Г.В Лепсверидзе (псевдоним- Григорий Лепс) к СМИ, которое без согласия артиста опубликовало в своем печатном издании его изображение. Московский городской суд, оставил в силе принятое в пользу истца решение нижестоящего суда и определил: «Суд правильно указал, что публичность профессии Г.В Лепсверидзе не влияет на оценку действий ответчика при применении ст. ст. 23, 24 Конституции РФ, ст. 150, 151 ГК РФ и не освобождает ответчика от обязанности получить согласие Г.В Лепсверидзе на распространение в СМИ сведений о его личной (частной) жизни. Из ст. 152.1 ГК РФ также не следует, что публичность профессии гражданина сама по себе является основанием для использования изображения гражданина другими лицами без согласия изображенного, такой случай в ст. 152.1 ГК РФ не указан.»

Второй довод заключается интересе в отношении истца со стороны общественности. В таком случае изображение истца может быть использовано без разрешения ввиду его значимости для общества. Также изображение может быть сделано на каком-либо публичном мероприятии.

В качестве примера можно привести дело, в котором газета использовала изображение известного артиста, полученное на публичном мероприятии, в сочетании с оскорбительным текстом, представленным, как поступившее в редакцию «письмо читателя». В апелляционном определении Московского городского суда от 02.08.2013 года, оставившем в силе решение первой инстанции об удовлетворении иска о защите права истца на изображение, указано: «... обнародование изображения истца под письмом читателя, высказывающего личное мнение о внешности певца, не может считаться общественным или публичным интересом, несмотря на то что истец является хорошо известной личностью. Действующее законодательство не предусматривает освобождение ответчика от ответственности за нарушение права на изображение по принципу общеизвестности лица» [10].

Третий довод, который можно встретить- изображение истца не было основным объектом съемки.

Так, в деле по иску певца к СМИ «Желтая газета», которое опубликовало изображение истца на публичном мероприятии, сопроводив это информацией личного характера, которая не могла относится к происходящему на изображении мероприятию. Измайловский районный суд г. Москвы, указал в решении, что «довод ответчика о том, что данная фотография сделана на концерте «Новая волна» в Юрмале аккредитованным фотографом, ... не может являться правомерным для использования данной фотографии не для описания событий указанного концерта», которое опубликовало изображение истца на публичном мероприятии, сопроводив это информацией личного характера, которая не могла относится к происходящему на изображении мероприятию [11].

Применительно к вышеописанному контексту, также интересным примером является дело, по иску Хрулёвой Е.В. (псевдоним - Елена Ваенга) к ответчику ОАО «Ньюс Медиа».СМИбыло опубликовано изображение артистки, сделанное на концерте без ее согласия, в сочетании с информацией о ее частной жизни. Московский городской суд решение отменил и постановил по делу новое решение, удовлетворив исковые требования, указав: «Довод ответчика о том, что фотография истицы, используемая в газете, была сделана в публичном месте, на концерте, в связи с чем её согласие на использование изображения не требовалось, также не может быть признан законным, поскольку пункт 2 статьи 152.1 ГК РФ об использовании без согласия гражданина его изображения, сделанного на публичном мероприятии, имеет существенную оговорку - если такое изображение не является основным объектом использования. Если изображение, сделанное на публичном мероприятии, является основным объектом использования, требуется согласие изображенного на использование такого изображения. На помещенной в газете «....» за .... г. фотографии истицы, наоборот, выделена крупным планом только истица, фон размыт, никакие другие лица или объекты не присутствуют, статья, которую иллюстрирует данное изображение, не рассказывает о каком-либо публичном мероприятии, в котором принимала участия истица, в связи с чем данное изображение истицы можно признать основным объек- 
том использования, что влечет за собой необходимость получения её согласия на использование этого изображения, однако, ответчик не представил доказательств получения такого согласия»[12].

В силу изложенного, можно сделать вывод о том, что на данный момент национальное законодательство РФ и правоприменительная практика обязывают субъектов правоотношений получать согласие на любое использование изображения гражданина в печатной продукции, за исключением изъятий, предусмотренных статьей 152.1 ГК РФ.

Также, как в литературе, так и в практике встречаются проблемные вопросы при использовании изображения гражданина в рекламной продукции.

Понятие «реклама» определено в пункте 1 статьи 3 Федерального закона от 13.03.2006 N 38-Ф3 «О рекламе». Под рекламой понимается информация, распространенная любым способом, в любой форме и с использованием любых средств, адресованная неопределенному кругу лиц и направленная на привлечение внимания к объекту рекламирования, формирование или поддержание интереса к нему и его продвижение на рынке. Как нами уже упоминалось, доктрина относит изображение гражданина как информационный объект, поэтому разумно считать, что оно подпадает под регулирование Федерального закона «О рекламе» [13].

В силу этого, М.Н. Малеина выделяет некоторые ограничения при создании и распространении рекламы: необходимо соблюдать авторские права при распространении рекламы, содержащей объект интеллектуальной собственности (статьи 1270, 1281, 1282 ГК РФ); соблюдать запрет на использование изображение лица без его согласия (статья 151.1 ГК РФ); запреты на использование определенных образов в рекламе определенных видов товаров, работ и услуг (статьи 5, 21, 26, 27 ГК РФ) [14].
При этом, использование изображения гражданина в рекламе, как правило, происходит за определенную плату, то есть на основании изъятия, предусмотренного подпунктом 3 пункта 1 статьи 152.1 ГК РФ: «согласие не требуется... когда гражданин позировал за плату» [7].

Но данное изъятие следует рассматривать исходя из объема, предоставленного гражданином согласия на использование. То есть, если гражданин согласился, что его изображение будет использовано одним способом и получил за это плату, использование данного изображения в иной цели, форме или иным способом без надлежащего согласия, является незаконным, так как изменится сфера использования изображения [14].

Подводя итоги анализа правовой охраны использования изображения гражданина, хотелось бы отметить некоторые аспекты.

Отсутствие нормативного понятия «изображение», приводит к необходимости исследования доктрины для определения специфики права гражданина на изображение и его использование. Это ведет к некоторой неопределённости при квалификации гражданских правоотношений на практике.

Также при анализе сложившийся судебной практики, можно сделать вывод о двух необходимых нововведениях. Первое- установление более четких рамок для согласия граждан на использование их изображения. Определение данного согласие как сделки, должно содержаться не в разъяснениях судебных органов, а закреплено нормативно. Второе- ни статьей 152.1. ГК РФ, ни судебной практикой высших судов не предусмотрен отзыв данного гражданином согласия на использование изображения. Данный механизм представляется необходимым способом защиты своих прав.

\section{ЛИТЕРАТУРА}

1. Постановление Пленума Верховного Суда РФ от 23 июня 2015 г. № 25 «0 применении судами некоторых положений раздела I части первой Гражданского кодекса Российской Федерации» // Российская газета. 2015.

2. Федеральный закон от 27.07.2006 № 149-Ф3 06 информации, информационных технологиях и о защите информации//Собр. законодательства Российской Федерации. 2006. № 31. ст. 3448.

3. Федеральный закон от 27.07.2006 № 152-Ф3// Собр. законодательства Российской Федерации. 2007. № 31. ст. 3451.

4. Омарова Ю.А. О гражданско-правовых средствах индивидуализации граждан // Российское право: Образование. Практика. Наука. 2017. № 4. С. 37

5. Мазаев Д.В. Охрана изображения гражданина в сети Интернет // Вестник Саратовской государственной юридической академии. 2016. № 6 (113). С. 104.

6. Гришаев С.П. Право гражданина на изображение // Гражданин и право. 2012. № 9. С.50.

7. Гражданский кодекс Российской Федерации (часть первая) от 30.11.1994 № 51-Ф3 (ред. от 16.12.2019) // Собр. законодательства Рос. Федерации. 1994. № 32. С. 3301.

8. Николаева А.А. Изображение гражданина: проблемы правового регулирования, использования, охраны и защиты: дис. ... канд. юрид. наук. 2014. С. 118.

9. 0 средствах массовой информации: закон от 27.12.1991 № 2124-I // Собр. законодательства Российской Федерации. 1992. № 7. ст. 300. 
10. Апелляционное определение Московского городского суда от 02.08.2013 по делу № 11-19242/2013 [Электронный ресурс] Режим доступа: https://mosgorsud.ru/mgs/services/cases/appeal-civil/details/fbc88ca3-a33b-46f0-b474-21f2a6770599?year=2013\&formType=fullForm (Дата 0бращения: 28.05.2020).

11. Решение Измайловского районного суда г. Москвы от 12.02.2013 года по делу № 2-446/13.

12. Апелляционное определение Московского городского суда от 08.02.2013 по делу № 11-1434/2013 [Электронный ресурс] Режим доступа: https://mosgorsud.ru/mgs/services/cases/appeal-civil/details/67bb283f-8eb8-4e42-9cad-984026e8ad25?year=2013\&formType=fullForm (Дата 0бращения: 28.05.2020).

13. Федеральный закон «0 рекламе» от 18.07.1995 № 108- Ф3 // Собр. законодательства Российской Федерации. 1995. № 30. ст. 2864.

14. Малеина М.Н. Использование в рекламе изображения гражданина: правовые основания и последствия: Октябрь // Закон: Октябрь. 2007. С. 22.

○ Сафин Никита Игоревич (safin99nikita@gmail.com), Проскурина Дарья Сергеевна (dariaproscurina@gmail.com).

Журнал «Современная наука: актуальные проблемы теории и практики»

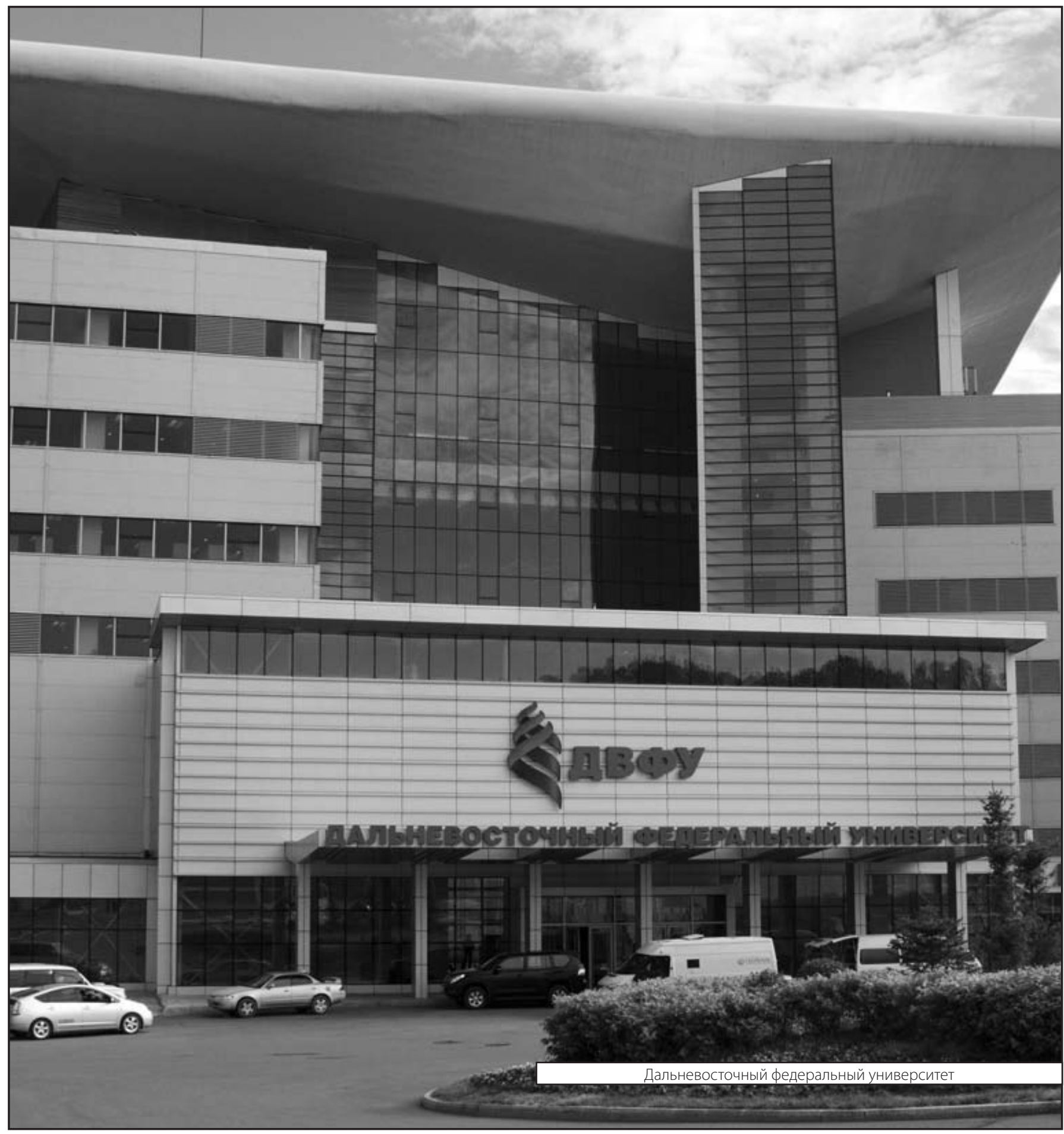

